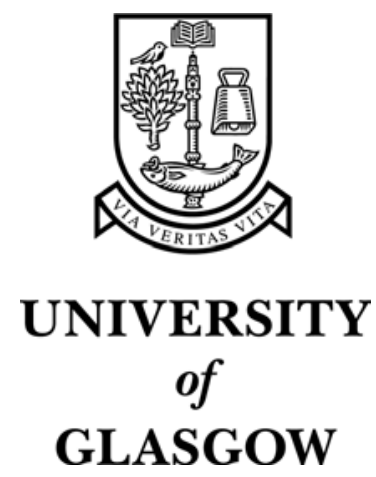

Rippon, J. and Martin, M. (2003) Supporting induction: relationships count. Mentoring and Tutoring 11(2):pp. 211-226.

http://eprints.gla.ac.uk/archive/00002211/ 


\section{Supporting Induction: Relationships Count}

\section{Introduction}

This paper examines the structural changes to the induction of teachers in Scotland using the perceptions of a group of final year student teachers. This group would be the first probationer teachers to experience revised arrangements for new teacher induction in 37 years. Their preferences and concerns are highlighted, as the new procedures roll out in schools nationwide, in an attempt to stress the importance of relationships to the success of the induction scheme. The argument put forward in this paper is based on the notion that personal intelligence is central to effective relationships and therefore crucially important in the context of this mentoring relationship. The views of our sample provide evidence to suggest that the quality of interactions between the mentor and the probationer teacher are paramount in providing a good induction experience. These views are substantiated by experiences in England and in induction literature elsewhere as described later. A synthesis of this evidence is used to make recommendations for those involved in supporting induction in schools, local authorities or teacher education institutions.

\section{Context}

The original process for inducting new teachers into the profession was established by The Teaching Council (Scotland) Act 1965. It created the General Teaching Council Scotland (GTCS) with its main task to prohibit the use of "uncertificated teachers" in Scottish schools. The GTCS went on to set up a register of all teachers and maintained its power to issue or withdraw provisional or full registration to them. The key features 
of the former probationary period are outlined in Figure 1. The main criticism levied at the probation process was the nature of the employment contracts given to probationer teachers. There was little consistency in terms of the duration or permanency of the posts in which probationers were deployed. There was no guarantee of support and development being given to probationers in these posts. Schools and local authorities were not held accountable for the induction experiences of their probationer teachers. There was no guarantee of uniformity in terms of the nature of support and guidance provided to probationers. This situation was highlighted in "A Teaching Profession for the $21^{\text {st }}$ Century" where inconsistent induction provision was referred to as "little short of scandalous"(p.7, SEED, 2000).

This provided the impetus for change to the induction process. The development of a benchmark framework for measuring teacher competency, across the profession, was already underway. The framework was consolidated with the development of the Standard for Full Registration (SFR) written to provide a framework for assessing probationer teachers. The SFR was to become the mandatory assessment tool used by mentors and school managers when considering each probationer's readiness for full registration with the General Teaching Council Scotland.

The result has been the creation of the Teacher Induction Scheme supported by a procedural framework. This framework sets out a minimum level of experiences for probationer teachers to work through, with a dedicated induction supporter or mentor, in pursuit of full registration and eligibility for a permanent teaching position. 
Figure 1

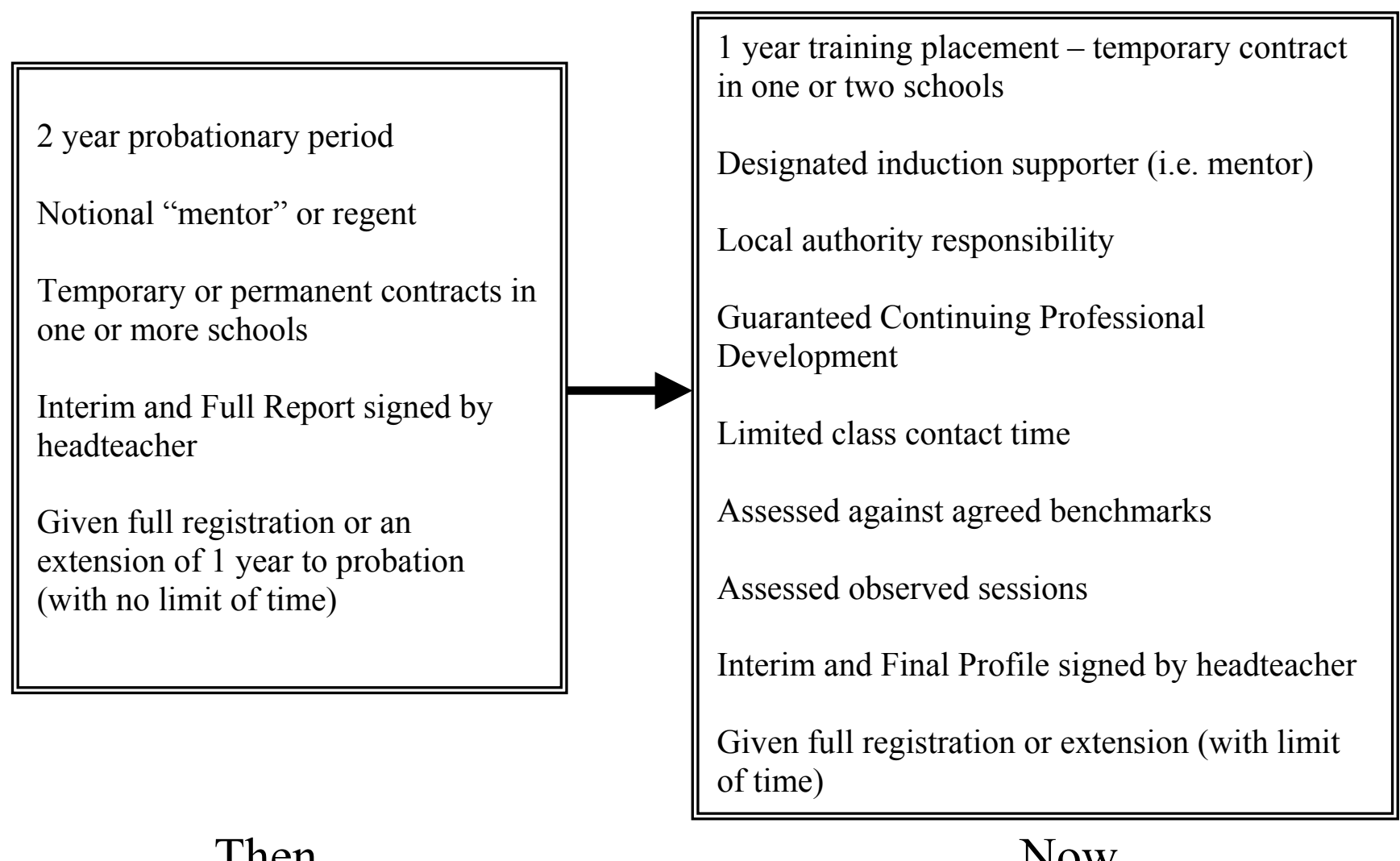

Each probationer teacher is employed in a training contract for one year. During this time $\mathrm{s} / \mathrm{he}$ is allocated an induction supporter. The induction supporter has been called "mentor" in many local authorities. The induction supporter is freed from class commitments for $1 / 2$ day per week to allow the supporter and probationer to work together. This allocation of time is funded by the Scottish Executive. The induction supporter is expected to hold regular meetings with the probationer; carry out assessed observations; provide support and facilitate professional development opportunities in this time. 
The probationer teacher is contracted to work to a restricted timetable (3.5 days per week). In the remaining 1.5 days, the probationer is expected to undertake Continuous Professional Development (CPD). The CPD activities include core activities (alongside other probationers); specific experiences (relevant to targets of the individual probationer or their school context); enhanced planning and preparation.

The probationer is formally assessed on 9 occasions throughout the training year. There will be termly reviews of performance against the SFR conducted with the induction supporter and/or the headteacher. These will be used to set development targets with the probationer or to complete the two Profile reports which are submitted to the GTCS. The Profiles are used as evidence to support the case for or against the award of full registration. The local authority has a responsibility to monitor the progression of probationers in relation to this framework.

At the time of our study, the SFR had come into the public domain in the form of the Consultation document (2001). The Teacher Induction Scheme had been launched and student teachers had been asked to register for a place. However, the final details of how it would operate and what it would entail did not emerge until after the completion of our project. It is in this context that the study of final year student teachers' views was undertaken. 


\section{Methodology}

The research study uses symbolic interaction as a conceptual framework (Blumer, 1969). It is used to explore the assumption that the Teacher Induction Scheme will not succeed based upon a deterministic operation of structures and procedures alone. It will depend upon the interaction of different "actors in the social arena" (i.e. the interaction of the probationer teacher and the induction supporter). The socialisation process impacts on probationer teachers' behaviour as they try to assimilate the culture of the school (Lortie, 1975), (Hargreaves \& Woods, 1984), (Huberman, 1993). The induction process plays its part in this socialisation role helping to perpetuate existing beliefs, standards and practices in schools. The importance of the mentor or induction supporter, and other supporting staff, in the socialisation of probationer teachers has been discussed (Ball, 2001), (Chubbuck et al, 2001), (Kelchtermans \& Ballet, 2001). The induction supporter guides probationer teachers towards holding particular values and demonstrating certain behaviours. These are enforced through the assessment process indicative of this formal induction scheme. This gives the supporter some power in shaping the profession; providing an initiation into the teaching body; and in providing access to full registration for individual probationer teachers. In re-defining mentors as the induction supporters, the role changes in the new scheme with the induction supporter providing support and carrying out competency assessment. Hence, the induction supporter becomes a gatekeeper to the teaching profession (Smith, 2001). This denotes a power relationship formalised by a set of mandatory procedures. This study considers how these procedural and power relationships can be tempered by developing the inter-personal dimension as 
probationer teachers and their induction supporters work together in schools. This is achieved using the voices of the final year student teacher sample

\section{Main Data Source}

The study was a collaborative endeavour between 2 Scottish universities. A survey questionnaire was devised using open and closed questions. Section 1 sought out demographic information such as gender, professional qualification, age and family status. Section 2 looked at the type of support new teachers sought during their induction placement. This section used a combination of open questions and items where students were asked to rank their preference from a list of choices. Section 3 examined their views of assessment processes. Section 4 explored Continuing Professional Development (CPD) needs using open responses to acquire their views.

\section{The Sample}

The questionnaire was piloted with a small group of students and amendments made accordingly. The main questionnaire was issued to the target group including all final year students on the Bachelor of Education, Postgraduate Primary and Secondary courses in the two universities (1136 students). There were 271 respondents to the survey representing $24 \%$ of the final year, student teacher cohort in the Teacher Education Institutions (TEI) studied. All participants were guaranteed confidentiality and anonymity. Neither students nor universities would be identified in any reports. The breakdown of the sample according to Initial Teacher Education course is given in Table 
I. This represented approximately $11 \%$ of probationer teachers entering the Teacher Induction Scheme in August 2002.

Table I: Breakdown of sample according to ITE course (\%)

\begin{tabular}{|c|c|}
\hline Course Title & \\
\hline Bachelor of Education & 14 \\
\hline PGCE (Primary) & 25 \\
\hline PGCE (Secondary) & 61 \\
\hline
\end{tabular}

\section{Focus Group Interviews}

The postal survey data and emergent themes were used to devise a semi-structured interview schedule. This was used with a small focus group taken from the original sample. A self-selected group of 8 participants discussed the issues raised in the postal survey. The interviews were recorded on audiotape and a summary transcript was compiled. This data was added to the findings produced by the qualitative data in the survey report.

\section{Discussion of Emerging Themes}

The information illicited from the study pointed to 3 distinct types of potential relationships developing between probationer teachers and their induction supporters. The first relationship is characterised by a minimalist interaction by the participants. Both probationer teacher and induction supporter fulfil their roles and responsibilities as 
dictated by the requirements of the formal procedures. This relationship is mechanistic and unresponsive to the needs and abilities of the probationer teacher; being driven by the demands of the induction scheme itself. It is described as the 'procedural relationship'.

The second relationship is characterised by the imbalance of power and influence held by the probationer teacher and the induction supporter. The induction supporter wields influence over the probationer teacher by controlling the initiation into the school culture and by having the power to deny access to the profession in controlling the legitimate assessment mechanisms for new teachers. The induction supporter will expect the probationer teacher to conform and fit in with existing practices in an apprenticeship model of induction. Support is geared towards remedying any shortfalls in this conformity. This is called the 'power relationship'.

The third relationship combines interactions which fulfill procedural requirements and develop a genuine partnership based on professional and inter-personal collaboration. This 'personal relationship' is described as most desirable to develop an effective mentoring relationship between probationer teachers and their induction supporter.

\section{Procedural Relationships}

The creation of a formally designated induction supporter has led to the establishment of a procedural relationship between the probationer teacher and induction supporter. The existence of the induction supporter post facilitates an expectation that there will be someone from whom probationer teachers can expect guidance and support. They know 
that the relationship is based on rights and responsibilities of both partners as set out in the guidance for schools (GTCS, 2002b). This relationship is not established as a result of choice and goodwill, rather as a fulfilment of obligations and entitlements, as framed in the guidance from the GTCS. This is a key change for probationer teachers and their mentors.

However, the introduction of the procedural dimension was welcomed by the student teacher cohort. 'Mentor support' was cited by $45 \%$ of the respondents as an important feature of an induction placement. This was more than double the percentage who valued Continuing Professional Development (CPD) opportunities in the induction year (20\%). When asked what format they would like the support to be given in, $48 \%$ chose formally arranged meetings between themselves and their induction supporter as their first choice. A further $21 \%$ expressed a preference for regular, informal meetings with their induction supporter. The focus group discussions gave some insight into the reasoning behind the preference for regular, individualized meetings between the probationer teacher and their induction. The respondents talked about their experiences on school placements and the difficulty in accessing busy professionals during the school day. Their aspirations for the revised scheme providing induction supporters with "time to spend with you discussing problems and how to deal with them" were made clear. Some expressed feelings of guilt when they were eating into their mentors' own preparation time. They stated that induction supporters "should have real time to deal with probationers". The provision of weekly meetings with an induction supporter goes some way to meet these aspirations. The Scottish Executive have accompanied each training placement with funding for their 
induction supporter to be released for $1 / 2$ day per week to facilitate regular support and assessment mechanisms to be put into operation.

Our respondents expressed concern that the support would be given by timetable rather than according to need. They suggested that intensive, weekly scrutiny from the outset would make it difficult for them to gain recognition as fully qualified teachers in school. "I don't want to feel like the student at the bottom of the pile." The student teachers perceived they would be seen as unable to take full responsibility if the support was too evident. They were keen to "feel part of the team from day one." For these reasons, they wanted the level of support to be varied at different points in the training placement. They hoped that "bigger spaces between meetings with the supporter" would occur and that "the relationship will change and develop" as the probation year progresses. Indeed, the respondents hoped that the relationship would progress towards one based on "friendship" and "being an equal member of staff, regardless of lack of experience".

The respondents were keen that the timetable of support did not marginalise any recognition of the diversity of needs felt by probationer teachers. Whilst the student teachers wanted a varied level of support during the training placement on a sliding scale of diminishing support in the latter stages, they worried about different probationers receiving different levels of support. Ironically, their concerns were not couched in terms of losing out on their entitlement of support. They were more concerned with potential messages transmitted if they requested the reinstatement of support or were seen to need 
more support than another probationer in school. "Preferences for different levels of support might be seen as one being more needy than the other."

The formalised timetable of induction support evoked conflicting responses from the respondents. They wanted to stake their claim to the right of regular access to induction supporters. Their experience on school placements has convinced them that this access can be difficult without formal provision being made. Nonetheless, they resented the different professional profile ascribed to them by exercising this right. It set them apart from their colleagues. The regularity was at times welcomed but did not give recognition to increasing competency as the induction year progresses. The support patterns remained unchanged (i.e. weekly throughout the session). This would seem to be the main criticism levied by the respondents against the recommended procedures.

Induction supporters have been charged with responsibility for undertaking systematic observation of the probationer teacher and providing feedback on performance in class and around the school. Feedback on performance was chosen as a key feature of induction process by $46 \%$ of the respondents; with $95 \%$ of the sample asserting that regular feedback on performance would be helpful or very helpful. The weekly allocation of time to induction supporters will allow regular, planned observations to take place and give some time to discussion of performance with the probationer teacher. This has proven to be the most highly rated aspect of teacher induction in England (Totterdell et al, 2002). A similar induction was introduced in England in 1999 allowing 
certain parallels to be drawn. In England, $89 \%$ of newly qualified teachers rated lesson observation to be useful or very useful.

It can be concluded that procedural arrangements for induction supporters and probationer teachers to work together are positive developments in new teacher induction. It allows the relationship between the supporter and probationer to develop on a formal basis. This helps to establish a consistent approach in providing support and guidance to probationer teachers replicated in schools across Scotland. It facilitates a guaranteed minimum of contact and legitimises the importance of developing a stable relationship on which to build robust support structures. This is done through giving public recognition to the time it takes to build a mentoring relationship in a work setting. However, the procedural dimension is unresponsive to individual needs and differences. It facilitates a mechanistic relationship which has to be tempered by an inter-personal approach which can take account of the sensitivities and perceptions experienced by some probationer teachers. It is especially important to consider this as early evaluations of the induction experience in England suggests that procedural provisions can be compromised in schools. Totterdell found $20 \%$ of newly qualified teachers had a less than satisfactory induction experience due to procedures not being fulfilled (Totterdell et al, 2002).

An interpersonal dimension allows recognition to be given to the needs of individual probationer teachers working in specific school contexts at different points in the induction year. It will take account of the probationer teacher's individual induction 
experience whatever procedures have been put into operation. This is provided most effectively when the induction supporter is aware of each probationer's hopes, fears and needs. They have to be aware of their own values, preferences and limitations too.

\section{Power Relationships}

The induction supporter has been charged with responsibility for carrying out regular, formal assessments of the probationer teacher in the form of observed sessions. A minimum of nine observed sessions is to take place in the training year. The introduction of this practice gives a different perspective to the role of the induction supporter from traditional "mentor" roles as outlined earlier. Attempts to offer guidance, advice and support can be overshadowed by formal assessments being undertaken to determine the probationer teacher's prospect of gaining full registration. The student teachers worried about seeking support from the person who would assess you. They suggested that needing support could be seen as a weakness to be reflected in future assessments. They were unsure if this situation would prove effective as they realised, "it would mean there would be no one to speak to who doesn't assess your performance”. The student teachers (31\%) were undecided as to whether both roles of support and assessment should be carried out by one person. Williams and Prestage's (2002) sample of newly qualified teachers (NQTs) expressed concern about the tension between these two roles.

In effect, the induction supporter has been given the potential to become another gatekeeper standing on the threshold of eligibility for full registration. There is an inbuilt tension in creating this dual role for the induction supporter. A small majority of our 
sample (53\%) was happy for the same person to undertake the support and assessment roles. Yet, $16 \%$ of the sample did not think this should be allowed. They explained "in $a$ situation where the person is unapproachable or holds a personal grudge, an unbiased person would make a better, fairer judgement" and "too many people failed placement due to personality clashes" to allow one person to hold the power over assessments contributing to their final registration as teachers. However, Totterdell (p.3, 2002) suggests that school staff in England are "reluctant to fail" new teachers if it prevents them from continuing in the profession.

It has been suggested that the power of assessment could escalate the trend for teachers to socialise new recruits into becoming mirror images of themselves in an apprenticeship model of training teachers (Bleach, 2001). Interestingly, the student teachers recognised the impact of this mode of training. As one commented, "One may fall into the bad habits of the mentor without an outside assessment to monitor progress." The apprenticeship model assumes there is one way to operate and it is the best way. This has been partially blamed for the teaching profession's inability to enact change and regenerate itself (Tickle, 2000). It is a model of teacher education which does not always facilitate diversity in teaching styles and approaches to develop according to individual strengths and interests. Probationer teachers could be compelled to conform to the dominant model of teaching to ensure their fully registered place in the profession. Smith (p.314, 2001) has suggested that most teacher mentors have a "strong sense of the sort of person who should or should not be allowed to become a teacher". Given the power 
dimension to the supporter-probationer relationship, it is not surprising our student teacher sample suggested, "for me the first year is about conforming to the school ethos".

Yet these concerns are tempered by the positive views of the $53 \%$ of the sample who were encouraged by both roles being carried out by their supporter. Many were pleased to find their profile reports would have more input from someone directly involved in their day-to-day work rather than dependent upon head teachers, many of whom had never seen their work first hand. They responded optimistically reinforcing the importance of a holistic relationship between the probationer and their supporter saying, "I feel this would be useful as this person could work closely with you and get to know you and your style". Others mentioned the importance of "continuity of approach, building up a working relationship". They state that the induction supporter will have " $a$ bigger picture on how I teach overall." Continuity and consistency can flourish where the procedural and power dimensions are countered by positive interpersonal relationships.

The organisational culture in school is bureaucratic and hierarchical. (Dreeben, 1988), (Lortie, 1975). This was recognised by our student teacher sample. They were keen to discard the label which they were ascribed as student teachers in school which put them firmly "at the bottom of the pile" and did not want to be "treated like a student" during their training placement. One respondent described how "statements in the staffroom can be designed to put you down, your views ignored". This is another example of how probationer teachers find themselves engaged in a power relationship during their first 
year in the profession. Already, they have internalised the dominant culture by asserting their changed position within the existing hierarchy. As probationer teachers, they wanted to affirm their move one step up the ladder from their position as student teachers. The existence of a designated induction supporter working weekly with the probationer may undermine the probationer's attempts to do this and establish their own identity as a "real teacher". Interestingly, one respondent referred to the induction supporter as a "probation officer", someone who would be out to control the behaviours and practices of the probationer in line with the culture of the school.

The organisational structure of the school helps to condition probationer teachers' expectations from an early stage. "It's good when you feel part of a team from day one, your ideas are valued and even passed on". The student teachers emphasised the importance of being spoken to by their Christian name not by their professional designation - "the student" or "the probationer". They wanted to be recognised as fully qualified teachers albeit not fully registered ones. Indeed, they wanted acknowledgement as a colleague stating, "a probationer should be seen as a colleague within the department not someone to be assessed all the time". It is the concept of "emerging colleagueship" which typifies their aspirations (Spindler and Biott, 2000). This sample expressed a desire to be labelled as teacher colleagues rather than student or probationer teachers. They wanted their contribution to the school to be acknowledged. They wished for the power relationship to shift as the year progresses or in their own words, "by its very nature the relationship will change and develop". The student teachers wanted the induction supporter "not to be too domineering". At best, induction supporters will 
facilitate the empowerment of individual probationers as they move towards full registration. It is not easy to accommodate this balance of power using the timetabled framework of procedures used in the GTCS guidance. It will be determined by the interpersonal skills of the induction supporter who has to be able to allow the probationer teacher to carve out their own identity within the school. The induction supporter has to be sensitive to this change. $\mathrm{S} /$ he has to be aware of the nature of the power relationships at work and its implications for the probationer. The induction supporter should be confident enough to share power with the probationer during the induction placement.

\section{3. 'Personal Relationships'}

In broad terms the study highlighted overwhelmingly the importance of the quality of relationships between the induction supporter and the probationer in the induction process. It also focused attention on the nature and extent of feedback. There was a clear message in both the qualitative and quantitative data about the importance of these aspects of the induction process to respondents. When asked to identify the desired personal and professional traits of induction supporters respondents were overwhelmingly more concerned with the former.

“Approachability" was mentioned, by $86 \%$ of respondents, to sum up a range of interpersonal skills and attitudes seen as desirable in this relationship. A summarised description is provided in Figure 2. Some respondents suggested the supporter should be, 'approachable and willing to take time to talk and offer advice' and 'sympathetic to the 
needs and problems facing new teacher'. They hoped for supporters, 'to respect you as an equal member of staff, regardless of lack of experience'.

Figure 2

\begin{tabular}{lllll}
\hline friendly & sympathetic & empathetic & understanding & honest \\
available & trustworthy & reliable & compassionate & helpful \\
reasonable & not domineering & fair & positive & patient \\
flexible & non judgemental & easy to talk to & good listener & genuine \\
\hline
\end{tabular}

This finding is reflected in other studies. In her manual for NQTs in England, Bubb (2000) has cited a similar range of comments made by new teachers about their tutors. Tickle (1994) provides a list of essential qualities of the teacher tutor which also reflect the same concerns about approachability. Stephenson (1995) argues that the emotional condition of student teachers, so crucial to the effectiveness of their school experience, is often dependent on the confidence gained from their mentoring relationship. Williams and Prestage (2002) also recognise this need in NQT's to feel genuinely supported and encouraged in their first year of teaching.

Given this backdrop, there is a powerful argument for an emphasis on personal, as well as academic or other intelligence, in the development of effective relationships between induction supporter and probationer. Gardner (1999) identified the notion of personal 
intelligence in his work on multiple intelligences. Goleman's work (1995) on emotional intelligence also points to the importance of self awareness of one's own and others' feelings, needs and concerns. Tickle (2000) focuses on the importance of a humanist perspective on the induction process which, he argues, can be lost if there is too strong an emphasis on managing the process. Explicit exploration of this important area is required if the mentoring relationship is to be effective.

This is particularly the case in relation to the sensitive issue of handling feedback on performance. It has been shown that our student teachers value regular feedback but many expressed concern about how it would be handled. They stated that, "You want to be involved in it, not have it done to you". Final year students have considerable experience of feedback in the context of school placements. They have clear ideas about when it is in a useful format, " criticism if put properly is no problem-identifying your mistakes in a positive light". The impact of the skills and attitudes of teachers and tutors in this area are well known to them. Their confidence and well being on school placements are greatly influenced by how this sensitive issue is handled as demonstrated by their aspirations "to be treated like a professional, as a human being".

The tension facing probationers and supporters would be less problematic if both were skilled in handling feedback. They should be trained in setting a context where criticism is welcomed and sought out, rather than something to be feared. The establishment of such a relationship requires skill and understanding and should be explored alongside the teaching of 'technique' in handling feedback. 
Straightforward, simple advice on technique for handling criticism is helpful to inexperienced probationers and their supporters alike. Experiential learning - role play, simulation, interactive sessions - is an effective model to use in this personal development. Rakos (1991) describes assertiveness training in terms of "behaviour rehearsal" using modelling, coaching and feedback techniques with participants.

However, there is a need for attention to a deeper level of learning than technique alone. The development of probationers would be better served if this kind of opportunity becomes part of their preparation and the preparation of their induction supporters.

\section{Implications}

\section{Principle-centred induction}

The creation of a procedural-led induction process has to be balanced by a set of clear principles for probationer teachers, induction supporters and induction managers to work to in carrying them out. It is not enough to follow a set of guidelines and operate a timetable of scheduled meetings. The induction process has to be guided by a recognition that probationer teachers are people; induction supporters are people. An attempt to personalise the induction process is required to maximise its impact in providing a thorough induction experience for each probationer teacher. This paper argues that the induction process has to become person-centred as well as procedural in its operation. This personal dimension can be added by a skilful induction supporter. The induction supporter has to get to know the probationer and negotiate an appropriate pathway for them to develop. S/he will be required to facilitate the development of a 
professional identity for the probationer teacher in the face of the competing demands made of them.

Probationer teachers and induction supporters hold different needs, expectations and aspirations. They bring these to the process. Such diversity will impact on the way the system will operate. This paper asserts that it cannot be "a one size fits all" arrangement for induction. Different approaches to teaching and learning to teach will need to be incorporated into the roll out of the induction scheme to assure progress for all probationer teachers in pursuit of becoming fully registered teachers. Indeed, it can be argued that to follow the procedure-driven model tenaciously does not facilitate differentiation within teacher education. It fits with an education system setting out to provide "one correct model teacher". It is implied that many routes to the same destination are not acceptable. Such principles should not exist in a profession trying to attract more recruits and regenerate itself.

For these reasons, the initial changes to the induction experience provided in the Teacher Induction Scheme are to be commended for creating a consistent framework for probationer teachers. It should be amended now to take account of probationer teachers who demonstrate a progression in their professional competence from the early stages. The Standard for Full Registration will facilitate this process when used with the Profiles collated during the course of the year. Their support should be less regular to facilitate their inclusion as a colleague within their schools. The weekly provision would remain for cases where little or no progression in competence is evident. 
The role of the induction supporter in interpreting and adapting the guidelines for this purpose is paramount. There will be a fine line between balancing the rights and entitlements of each probationer teacher with the specific needs and contexts in which each probationer is operating. The ability to be even-handed, personable and flexible in the operation of the framework for achieving full registration cannot be under-estimated. The job of the induction supporter, especially in this first year, will be a challenge.

\section{$\underline{\text { Person Specification }}$}

It becomes apparent that the personal and professional skills of the induction supporter will be vitally important to the success of the Teacher Induction Scheme. As well as having to negotiate between the procedural and the personal dimensions of the process, s/he will have to be aware of the power relationships at work. They have to understand their power as a gatekeeper and use it judiciously. Their influence on the socialisation of the probationer teacher into the school culture and their place on the hierarchical ladder has to be acknowledged. They have to ensure the probationer teacher has the room to develop their own style within this culture. It is argued here that the induction supporter should not be predisposed to enforcing their values, beliefs and practices on the probationer teacher as part of the assessment process. The induction supporter has to be sensitive to different needs at different times and allow opportunities for the probationer teacher to operate as a colleague amongst other staff. The demands on the induction supporter are immense. 
For these reasons, it is important that the post of the induction supporter is not allocated haphazardly. The student teachers stressed the importance of someone "who really wanted to do it" and "not forced to do it". The speed of the implementation of the Teacher Induction Scheme in its first year has led to the post going to many who held responsibility for probationers under the old system or to "unsuspecting volunteers". However, the nature of the relationship between probationer teacher and "mentors" has changed as outlined above. This new context suggests that the qualities and skills of the induction supporter have changed too. The induction supporter role needs to be given further consideration. This paper uses the voices of the student teachers to give an indication of the job specification to be used in recruiting induction supporters (Figure 3). This may help some teachers consider themselves as potential induction supporters. This person specification or a modified version may be used in recruitment by school or local authority managers. Clearly, the remit of the induction supporter cannot be lumped on to existing remits. It involves a different role to any others existing previously. Therefore, it should be looked at carefully under these new conditions.

\section{$\underline{\text { Staff Development }}$}

There is a need for systematic training for induction supporters and probationer teachers in Scotland. This training has to go beyond consideration of the procedural arrangements. Staff development opportunities have to include deliberation of the personal and power relationships at work. This paper has argued that work on the development of personal intelligences, as well as the skills and techniques used in their development, should become a major feature of staff development. It recommends a 
detailed exploration of the techniques, as outlined above, is made available to probationers and their supporters. However the danger is that technique can become the main preoccupation with those who would wish to handle feedback more effectively. This paper argues that while technique is important, an understanding of the importance of self-awareness and empathy is much more influential in the success or failure of feedback. Staff development therefore should focus, first and foremost, on the principles underpinning the nature of the relationship between newly qualified teachers and their induction supporters.

On one side the supporter needs to recognise the rights of the probationer to be treated with respect and trust, to be an active partner in dialogue and to be given effective feedback in an honest, sensitive way. On the other side, the supporter has the rights to give constructive feedback, to be listened to and taken account of. On both sides there is a responsibility to meet the requirements of the system to allow the probationer to met the Standard for Full Registration. The best way to achieve this is to help both probationers and their supporters to be aware of and understand the importance of the quality of the relationship, the attitudes and behaviour of those involved and the interpersonal skills required.

\section{Conclusion}

This paper has demonstrated that student teachers have clear expectations of the procedural arrangements for an effective induction placement. To some extent, these expectations have been met by the framework for induction used in schools and local 
authorities today. In theory, the rights and entitlements of probationer teachers have been safeguarded through these guidelines. Student teachers have been shown to hold equally strong views on what makes for an effective mentoring relationship. Their views are characterised by an awareness of the power dimensions involved. This relationship's success is determined by the interplay of personal intelligences and the skills of the participants. This paper asserts that the development of these understandings should not be left to chance. 
Figure 3: Person Specification (As generated by a study of the voices of Scottish student teachers)

\begin{tabular}{|c|c|c|}
\hline Induction Supporter & Essential Attributes & Desirable Attributes \\
\hline \multicolumn{3}{|l|}{ Approachability } \\
\hline Inclination & $\begin{array}{l}\text { Willing to work with probationer } \\
\text { teachers. }\end{array}$ & $\begin{array}{l}\text { Expresses a desire to work with probationers } \\
\text { and demonstrates a keen interest and } \\
\text { knowledge of issues associated with them. }\end{array}$ \\
\hline Time & $\begin{array}{l}\text { Use time available to deal with } \\
\text { probationers' concerns. }\end{array}$ & $\begin{array}{l}\text { Make time to spend with probationer teachers } \\
\text { to support, guide and discuss issues with them } \\
\text { as they arise. }\end{array}$ \\
\hline Listening & $\begin{array}{l}\text { Willing to spend time listening to } \\
\text { probationer's views and concerns. }\end{array}$ & $\begin{array}{l}\text { Demonstrate the desire to listen actively to } \\
\text { probationer teachers, taking account of their } \\
\text { views and concerns in practice. }\end{array}$ \\
\hline Empathy & $\begin{array}{l}\text { Have an appreciation of the } \\
\text { apprehension felt by most probationer } \\
\text { teachers. }\end{array}$ & $\begin{array}{l}\text { Show understanding of areas of concern to } \\
\text { probationer teachers and ability to find out } \\
\text { about personal and professional concerns of } \\
\text { individuals. Willing to stand up for } \\
\text { probationers within the school/authority } \\
\text { setting. }\end{array}$ \\
\hline Partnership & $\begin{array}{l}\text { Have the skills to work with } \\
\text { probationer teachers as professional } \\
\text { colleagues. }\end{array}$ & $\begin{array}{l}\text { Have a genuine interest in collaborating with } \\
\text { probationer teachers, in an equal partnership, } \\
\text { to consolidate and challenge personal and } \\
\text { professional practices. }\end{array}$ \\
\hline \multicolumn{3}{|l|}{ Teaching Credibility } \\
\hline $\begin{array}{l}\text { Teaching } \\
\text { Competence }\end{array}$ & Be a positive teaching role model. & $\begin{array}{l}\text { Be a positive role model in your relationships } \\
\text { with pupils, in the delivery of the curriculum } \\
\text { and in terms of organisation in your own class } \\
\text { practices. Be able to share and explain your } \\
\text { teaching practices with others. }\end{array}$ \\
\hline Teaching Reputation & $\begin{array}{l}\text { Be well regarded by pupils, } \\
\text { colleagues, school managers and } \\
\text { parents. }\end{array}$ & $\begin{array}{l}\text { Have a proven track record of high } \\
\text { achievement as a teacher, staff member and } \\
\text { mentor. }\end{array}$ \\
\hline \multicolumn{3}{|c|}{ Professional Knowledge and Authority } \\
\hline $\begin{array}{l}\text { Educational } \\
\text { Knowledge }\end{array}$ & $\begin{array}{l}\text { Possess up-to-date educational } \\
\text { knowledge and skills. }\end{array}$ & $\begin{array}{l}\text { To possess up-to-date educational knowledge, } \\
\text { be able and willing to share it and the } \\
\text { underpinning philosophies and/or principles } \\
\text { with others. }\end{array}$ \\
\hline School Knowledge & $\begin{array}{l}\text { Be aware of wider school issues and } \\
\text { procedures. }\end{array}$ & $\begin{array}{l}\text { Be able and willing to explain whole school } \\
\text { policy and procedures to probationer teachers, } \\
\text { guide them to relevant sources of information } \\
\text { or personnel. }\end{array}$ \\
\hline \multicolumn{3}{|l|}{ Motivational Skills } \\
\hline Observation & $\begin{array}{l}\text { Have an awareness of key professional } \\
\text { skills in the classroom. }\end{array}$ & $\begin{array}{l}\text { Able to identify and evaluate professional } \\
\text { abilities and personal qualities. }\end{array}$ \\
\hline Feedback & $\begin{array}{l}\text { Able to give sound advice and } \\
\text { direction to probationer teachers. }\end{array}$ & $\begin{array}{l}\text { Able to establish a genuine, honest dialogue } \\
\text { about performance balancing courage with } \\
\text { consideration for the probationer teacher. }\end{array}$ \\
\hline Enthusiasm & $\begin{array}{l}\text { Able to demonstrate a love of } \\
\text { teaching. }\end{array}$ & $\begin{array}{l}\text { Able to collaborate with others generating an } \\
\text { enthusiastic and confident approach to } \\
\text { teaching. }\end{array}$ \\
\hline \multirow[t]{5}{*}{ Other } & \multicolumn{2}{|l|}{ Be honest. } \\
\hline & \multicolumn{2}{|l|}{ Be fair. } \\
\hline & \multicolumn{2}{|c|}{ Have a personal identity as well as a professional identity. } \\
\hline & \multicolumn{2}{|l|}{ Have a sense of humour. } \\
\hline & \multicolumn{2}{|l|}{ Respect others and their feelings. } \\
\hline
\end{tabular}


Supporting Induction: Relationships Count!

\section{$\underline{\text { References }}$}

Ball, S. (1987) The Micro-politics of the School: Towards a theory of school organization (London: Methuen).

Bleach, K. (2001) The Induction and Mentoring of Newly Qualified Teachers: a deal for new teachers (London: David Fulton Publishers).

Blumer, H. (1969) Symbolic Interactionism: perspective and method (Prentice Hall).

Bubb, S. (2001) A Newly Qualified Teacher's Manual (London: Fulton).

Chubbuck, S. M., Clift, R. T., Allard, J. and Quinlan, J. (2001) Playing it Safe as a Novice Teacher: Implications for Programs for New Teachers. Journal of Teacher Education, 52(5), pp.365-376.

Dreeben, R. (1988) The School as a Workplace. In Ozga, J. (ed.) Schoolwork: Approaches to the Labour Process of Teaching (Milton Keynes: Open University Press).

Gardner, H. (1999) Intelligence Reframed: Multiple Intelligences for the $21^{\text {st }}$ Century (New York: Basic Books).

Goleman, D. (1995) Emotional Intelligence (London: Bloomsbury). 
Supporting Induction: Relationships Count!

General Teaching Council Scotland (2002a) The Standard for Full Registration. (Edinburgh: SEED).

General Teaching Council Scotland (2002b) Achieving the Standard for Full Registration: Guidance for Schools (Edinburgh, SEED).

Hargreaves, A. and Woods, P. (eds.) (1984) Classrooms and Staffrooms: the sociology of teachers and teaching ( Milton Keynes: Open University Press).

Independent Committee of Enquiry into Professional Conditions of Teachers (Scotland) (2000) A Teaching Profession for the $21^{\text {st }}$ Century (Edinburgh: Stationery Office).

Kelchtermans, G. and Ballet, K. (2002) The Micro politics of teacher induction: A narrative-biographical study on teacher socialization, Teaching and Teacher Education 18 , pp.105-120.

Lortie, D. (1975) Schoolteacher: A Sociological Study (Chicago: University of Chicago Press).

Nias, J. (1989) Staff Relationships in the Primary school: A study of organizational cultures (London: Cassell). 
Rakos, R.F. (1991) Assertive Behaviour: Theory, Research and Training (London:

Routledge).

Smith, P. (2001) Mentors as Gate-keepers: an exploration of professional formation, Educational Review 53(3), pp.313-324.

Stephenson, J. (1995) Significant others: the primary student view of practice in schools, Educational Studies, 21( 3), pp 323- 335.

Tickle, L. (2000) Teacher Induction: the way ahead (Buckingham: Open University Press).

Totterdell, M., Heilbronn, R., Bubb, S. and Jones, C. (2002) Evaluation of the Effectiveness of the Statutory Arrangements for the Induction of Newly Qualified Teachers (London:Department for Education and Skills).

Williams, A. and Prestage, S. (2002) The Induction Tutor: mentor, manager or both?, Mentoring and Tutoring, 10(1), pp.35-46. 